\title{
OUTCOME OF PATIENTS WITH FLT3 MUTATED ACUTE MYELOID LEUKEMIA IN FIRST RELAPSE
}

\author{
Farhad Ravandi ${ }^{1}$, Hagop Kantarjian ${ }^{1}$, Stefan Faderl ${ }^{1}$, Guillermo Garcia-Manero ${ }^{1}$, Susan \\ O’Brien ${ }^{1}$, Charles Koller ${ }^{1}$, Sherry Pierce ${ }^{1}$, Mark Brandt ${ }^{1}$, Deborah Kennedy ${ }^{2}$, Jorge Cortes ${ }^{1}$, \\ and Miloslav Beran ${ }^{1}$ \\ ${ }^{1}$ Department of Leukemia, University of Texas - M. D. Anderson Cancer Center, Houston, TX, \\ USA
}

${ }^{2}$ Cephalon Oncology, Frazer, PA, USA

\begin{abstract}
Mutations of Fms-like tyrosine kinase-3 (FLT3) have been described in about 30\% of patients with acute myeloid leukemia (AML) and are associated with a shorter disease-free and overall survival after initial therapy. We sought to examine whether the presence of these mutations in relapsed disease was also associated with a poor response to salvage chemotherapy by comparing the outcome of 34 patients with diploid cytogenetics and mutated FLT3 (internal tandem duplication mutation - ITD) to 69 patients with normal karyotype and wild type FLT3 (FLT3WT) in first relapse. On univariate analysis, patients with mutated FLT3 were less likely to achieve a CR to first salvage compared to FLT3-WT patients ( $24 \%$ vs. $41 \%$; $\mathrm{p}=0.09$ ). Furthermore, survival was longer for the FLT3-WT patients achieving a second CR after salvage compared to FLT3-mutated patients ( $\mathrm{p}=0.017$ ). Overall, patients with mutated FLT3 had a shorter survival from the time of relapse compared to those with FLT3-WT ( $<0.001)$. The adverse prognostic impact of FLT3 mutations appears to persist beyond the initial treatment.
\end{abstract}

\section{Keywords}

Acute myeloid leukemia; FLT3 mutations; relapse; outcome

\section{INTRODUCTION}

Fms-like tyrosine kinase-3 (FLT3) and Its ligand (FL) is important in progenitor cell proliferation and differentiation. ${ }^{1}$ Expression of FL and FLT3 has been demonstrated in a number of human leukemia cell lines of both myeloid and lymphoid lineage. ${ }^{2-4}$ FLT3 is also expressed in primary leukemia cells in a number of hematological malignancies..$^{3,5-7}$ As a

\footnotetext{
(C) 2009 Elsevier Ltd. All rights reserved.

Corresponding Author: Farhad Ravandi, MD, Department of Leukemia, The University of Texas M.D. Anderson Cancer Center, 1515 Holcombe Blvd, Unit 428, Houston, TX, 77030, USA, Tel: 713-745-0394, Fax: 713-794-4297, fravandi@ mdanderson.org.

Publisher's Disclaimer: This is a PDF file of an unedited manuscript that has been accepted for publication. As a service to our customers we are providing this early version of the manuscript. The manuscript will undergo copyediting, typesetting, and review of the resulting proof before it is published in its final citable form. Please note that during the production process errors may be discovered which could affect the content, and all legal disclaimers that apply to the journal pertain.
} 
result of ligand binding, FLT3 receptor dimerizes, resulting in activation of its tyrosine kinase domain, receptor autophosphorylation, and recruitment of downstream signaling molecules such as signal transducer and activator of transcription-5a (STAT-5a), and the MAP kinase pathways leading to proliferative and pro-survival effects. ${ }^{1,8}$

Somatic mutations of FLT3 involving internal tandem duplications (ITDs) in the juxtamembrane domain of the receptor or point mutations in the activation loop occur in approximately $30 \%$ of patients with newly diagnosed AML. ${ }^{9-13}$ and, in the case of ITDs, are associated with shorter response duration and higher cumulative incidence of relapse. ${ }^{12,14-17}$ The prognostic significance of tyrosine kinase point mutations is less clear with conflicting reports on these mutations being associated with a poorer or more favorable outcome. ${ }^{18-20}$ These FLT3 mutations commonly occur in patients with diploid cytogenetics, lead to constitutive activation of FLT3 in a ligand-independent manner and contribute to the leukemic transformation. ${ }^{212,14-17}$ The high incidence of these activating mutations as well as their association with a poor prognosis has led to the clinical development of a number of tyrosine kinase inhibitors with significant in vitro activity in myeloid leukemia cell lines and primary cells. $^{22-27}$

The impact of FLT3 mutations on the outcome of therapy for relapsed AML is not known. From hereon we refer to such treatment as "salvage therapy". This is of particular relevance in trials examining the use of FLT3 kinase inhibitors in patients with AML in first relapse. ${ }^{28}$ We examined the effect of the presence of FLT3 ITD mutations on the response to salvage therapy in patients with diploid cytogenetics (CR or not). The intensity of induction therapy of newly diagnosed disease, age, duration of the first remission and intensity of salvage regimens were also considered in the evaluation of the outcome. 29,30

\section{MATERIALS AND METHODS}

\section{Patients}

We analyzed data from 109 patients with diploid karyotype, FLT3 mutated AML treated at the University of Texas - M D Anderson between 1995 and 2004. Only patients with FLT3 ITD mutations were included for this analysis. A group of 221 patients with verified FLT3 wild type AML treated during the same period were also analyzed for comparison. Patients with cytogenetic abnormalities including those with APL were excluded; this includes all the diploid patients with available FLT3 data seen during the specified period. Table 1 summarizes the characteristics of patients in the study including their response to induction chemotherapy, duration of their first CR, as well as others. Similar remission rate in both groups but shorter remission duration in the FLT3 mutated patients suggests that our patients were representative of those reported in the literature. ${ }^{10,15}$

\section{Initial induction regimens}

At initial presentation, all patients were treated without consideration of their FLT3 status. Induction therapy consisted of either high dose ara-C ( $\geq 1 \mathrm{~g} / \mathrm{m}^{2} /$ dose $)$ in combination with other drugs such as idarubicin with or without fludarabine, or topotecan and cyclophosphamide; a few patients received the DCTER regimen. ${ }^{31}$ A minority of patients 
received investigational agents including clofarabine, alone or with low dose cytarabine, or gemtuzumab ozogamicin with or without IL-11. Patients achieving CR received up to 6 postremission courses of therapy, generally similar to what they received for induction but with reduced dose intensity. Of note, only 4 patients (1 FLT3-mutated and 3 FLT3-WT) underwent an allogeneic stem cell transplant in first CR.

CR was achieved in $61 \%$ of patients with FLT3-mutated AML and $63 \%$ of those with wild type FLT3. Primary resistant disease was present in 24\% of FLT-3-mutated and in $19 \%$ of FLT-3 wild type patients. With a median follow up of 196 weeks (range, $4-335$ weeks) for the FLT3-mutated cohort, the median disease free survival (DFS) was 42 weeks and median overall survival (OS) 32 weeks. For the patients with wild type FLT3, with median follow up of 189 weeks (range, $8-451$ weeks), the median DFS and OS were 62 weeks and 72 weeks, respectively ( $\mathrm{p}$ values for DFS 0.014 and for OS $<0.001$ ). The significantly inferior outcome of patients with FLT3 mutations is in agreement with reports in the literature as well as with our previous report on the impact of FLT3 mutation on the outcome of induction therapy in diploid AML patients. ${ }^{32}$

\section{Study population}

From the above specified patient populations, 127 patients with known FLT3 status who achieved CR of at least 4 weeks duration and subsequently relapsed were further analyzed (Table 1). On their initial presentation, the majority of these patients $(103 ; 81 \%)$ received intensive cytoreductive induction regimens including high dose cytarabine (HIDAC) in combination with idarubicin $(\mathrm{I})(\mathrm{n}=49)$, fludarabine $(\mathrm{F})(\mathrm{n}=5), \mathrm{F}+\mathrm{I}(\mathrm{n}=21)$, daunorubicin $(n=4)$ or topotecan and cyclophophamide $(n=24)$. An additional 7 patients received intensive combination chemotherapy (DCTER). The remaining 17 patients (13\%) received miscellaneous induction regimens of intermediate intensity with the majority receiving clofarabine low dose cytarabine, gemtuzumab ozogamicin, or cloratezine (as their treating physician felt they were not candidates for more intensive chemotherapy).

\section{Polymerase Chain Reaction assay of FLT3 mutational status}

Genomic DNA from bone marrow samples was isolated using the Autopure extractor (QIAGEN/Gentra, Valencia, CA). FLT3 ITD mutations were determined by a semiquantitative DNA-based polymerase chain reaction-capillary electrophoresis (PCR-CE) assay. ${ }^{33}$ The sensitivity of the assay for mutation detection was $1 \%$ as determined by dilution studies.

\section{Statistical methods}

Survival curves were plotted by the Kaplan-Meier method and compared using the log-rank test. Differences in subgroups by different covariates were evaluated using the chi-square test for nominal values, and the Mann-Whitney $U$ for continuous variables. 


\section{RESULTS}

\section{Follow up after first $\mathrm{CR}$ and salvage therapy}

The median follow-up for the study patients from the time of relapse is 196 weeks and 14 patients are still alive. Forty seven patients with mutated FLT3 relapsed and 34 received salvage chemotherapy. In the FLT3 wild type cohort, 80 patients relapsed and 69 received salvage chemotherapy. The intensity of salvage regimens was comparable in the two cohorts (total of 103 patients) consisting of intensive combination chemotherapy regimens in 64 patients (62\% of total; HiDAC-based in 50\%, and other intensive regimens including allogeneic transplant in 12\%). The remaining 39 patients (38\%) received miscellaneous therapies mostly consisting of single agents often in the setting of phase I/II trials as they were considered not to be able to tolerate the more intensive regimens. Nine patients received no further therapy, 4 received a FLT3 inhibitor and were excluded, and 11 were lost to follow-up. Overall, 12 patients (12\%) received an allogeneic stem cell transplant after first relapse, 10 with FLT3 wild type disease and 2 FLT3 mutated. The summary of patient and treatment information is presented in Tables 2 and 3 ,

\section{Response to salvage therapy}

Of the 127 relapsed patients, 107 (92\%) received salvage chemotherapy. Twenty patients were not treated or were lost to follow-up and 4 received therapy including CEP701 on a trial and were excluded (Table 2). The response to salvage therapy in the remaining 103 patients stratified by the FLT3 status at diagnosis is summarized in table 3. A higher CR rate was observed in patients with wild type FLT3.(p=0.09). With low occurrence of treatmentassociated early deaths, resistance accounted for most of the treatment failures. This outcome was more frequent in patients with FLT3 mutation ((Table 3) although the difference did not reach statistical significance. Although age is potentially another predictor of outcome, the two groups were very similar in their age distribution. The patients varied not only according to FLT3 status but also according to duration of first remission (CR1) and type of salvage therapy received. Both these covariates are potential predictors for second CR. Thus we accounted for both in our analyses. We evaluated patients by their CR1 duration ( $>1$ to $<12$ months and 12 months or longer). We categorized intensive salvage therapy as either (1) allogeneic transplant, or high-dose cytarabine (HDAC) with or without additional agent(s), (2) other intensive regimens consisting of drug combination not including high dose cytarabine, or investigational single agents such as clofarabine cytarabine. The last group (3) received a variety of, primarily, single agents often given in a phase I or II settings or low doses of conventional single agents and is hereafter referred to as "miscellaneous".

We therefore, created six groups defined by duration of CR1 and type of salvage therapy with relevant response data for each group summarized in Table 4. In groups defined by CR1 duration, the above-noted CR rates were comparable to those observed in the 421 patients given the same salvage therapy during the study period but in whom flt 3 status was unknown (data not shown). 
Overall CR rates were 8/34 (24\%) in patients with mutated FLT3 and 26/69 (38\%) in patients with wild-type FLT3 and the differences were not statistically significant ( $\mathrm{p}=0.09$ ) (Table 4). The main cause of failure was resistance (rather than early death) in both FLT3 mutated and wild type groups with resistant disease appearing more frequently in patients with FLT3 mutation (65\% vs 48\%, respectively). CR rates were also lower in patients with mutated FLT3 who received transplant or HiDAC for first salvage:5/19 (26\%) vs. 23/45 (51\%). Although the numbers are small, the tendency for a lower CR rate in mutated FLT3 disease was seen in patients who were transplanted or received a HDAC-based regimen after either a CR1 duration of $<12$ months or $\geq 12$ months. The one scenario among the six shown in the table 4 where mutated FLT3 was associated with a higher CR rate was with a CR1 duration $<12$ months and miscellaneous salvage therapy. However, this finding seems likely to be due to a particularly poor outcome in wild-type disease given miscellaneous agents as well as small numbers of the patients treated. Indeed, the most striking contrast in the table is between patients with wild-type FLT3 who received trans/HDAC or miscellaneous regimens after CR1dur < 12 months (CR rates $11 / 26$ vs. 1/11, respectively).

Overall, patients with FLT3 WT had a significantly longer survival from the time of relapse than patients with mutated FLT3 ( $<<0.001$ )(Figure 1a).. Although achieving CR is of primary importance for the subsequent course of the disease, remission duration is closely linked to the quality of life and survival. The data on second CR duration and overall survival from relapse, summarized in Fig $1 \mathrm{~b}, \mathrm{c}, \mathrm{d}$ further suggest a negative impact of FLT3 mutation on the results of salvage chemotherapy. Because of the limited size of the subcohorts we felt that a detailed presentation of CR 2 duration and survival data for each cohort would not be meaningful.

\section{DISCUSSION}

The small sample sizes in this report led to several possible oversimplifications. First, it is likely that there is a continuous relationship between CR1 duration and response to salvage therapy, i.e. the longer CR1 duration the higher the likelihood of response to salvage, rather than the binary division shown here. Second, combining allogeneic transplant with HDACcontaining salvage regimens is completely empirical (although the same is not true of grouping all HDAC-containing salvage regimens).Third, although none are as predictive as CR1 duration, other covariates, e.g. age and cytogenetics, that may have an effect on probability of response to salvage therapy have not been evaluated.

In this study, all patients had diploid karyotype and we only evaluated the patients with ITD mutations. Although the median age of patients with FLT3 mutation was lower, this was not statistically significant. The small sample size did not allow a multivariate analysis to determine if FLT3 status was an independent predictor of salvage CR rate or survival after relapse. Another flaw with our report is that it assumes that FLT3 status at initial diagnosis and at relapse are identical. It has been suggested that in a minority of patients FLT3 status is different at relapse although this may be due to variations in sampling. ${ }^{34}$ 
Despite these issues, our results do suggest that the prognostic impact of mutated Flt3 is not limited to newly-diagnosed AML and its presence may have an adverse effect on response in the setting of relapse, and is associated with shorter survival after relapse.

\section{REFERENCES}

1. Gilliland DG, Griffin JD. The roles of FLT3 in hematopoiesis and leukemia. Blood. 2002 Sep 1; 100(5):1532-1542. [PubMed: 12176867]

2. Brasel K, Escobar S, Anderberg R, et al. Expression of the flt 3 receptor and its ligand on hematopoietic cells. Leukemia. 1995 Jul; 9(7):1212-1218. [PubMed: 7630197]

3. Drexler HG. Expression of FLT3 receptor and response to FLT3 ligand by leukemic cells. Leukemia. 1996 Apr; 10(4):588-599. [PubMed: 8618433]

4. Turner AM, Lin NL, Issarachai S, et al. FLT3 receptor expression on the surface of normal and malignant human hematopoietic cells. Blood. 1996 Nov 1; 88(9):3383-3390. [PubMed: 8896403]

5. Birg F, Courcoul M, Rosnet O, et al. Expression of the FMS/KIT-like gene FLT3 in human acute leukemias of the myeloid and lymphoid lineages. Blood. 1992 Nov 15; 80(10):2584-2593. [PubMed: 1384791]

6. Carow CE, Levenstein M, Kaufmann SH, et al. Expression of the hematopoietic growth factor receptor FLT3 (STK-1/Flk2) in human leukemias. Blood. 1996 Feb 1; 87(3):1089-1096. [PubMed: 8562934]

7. Stacchini A, Fubini L, Severino A, et al. Expression of type III receptor tyrosine kinases FLT3 and KIT and responses to their ligands by acute myeloid leukemia blasts. Leukemia. 1996 Oct; 10(10): 1584-1591. [PubMed: 8847893]

8. Levis M, Small D. FLT3: ITDoes matter in leukemia. Leukemia. 2003 Sep; 17(9):1738-1752. [PubMed: 12970773]

9. Nakao M, Yokota S, Iwai T, et al. Internal tandem duplication of the flt3 gene found in acute myeloid leukemia. Leukemia. 1996 Dec; 10(12):1911-1918. [PubMed: 8946930]

10. Thiede C, Steudel C, Mohr B, et al. Analysis of FLT3-activating mutations in 979 patients with acute myelogenous leukemia: association with FAB subtypes and identification of subgroups with poor prognosis. Blood. 2002 Jun 15; 99(12):4326-4335. [PubMed: 12036858]

11. Yamamoto Y, Kiyoi H, Nakano Y, et al. Activating mutation of D835 within the activation loop of FLT3 in human hematologic malignancies. Blood. 2001 Apr 15; 97(8):2434-2439. [PubMed: 11290608]

12. Abu-Duhier FM, Goodeve AC, Wilson GA, et al. FLT3 internal tandem duplication mutations in adult acute myeloid leukaemia define a high-risk group. Br J Haematol. 2000 Oct; 111(1):190_ 195. [PubMed: 11091200]

13. Abu-Duhier FM, Goodeve AC, Wilson GA, et al. Identification of novel FLT-3 Asp835 mutations in adult acute myeloid leukaemia. Br J Haematol. 2001 Jun; 113(4):983-988. [PubMed: 11442493]

14. Frohling S, Schlenk RF, Breitruck J, et al. Prognostic significance of activating FLT3 mutations in younger adults (16 to 60 years) with acute myeloid leukemia and normal cytogenetics: a study of the AML Study Group Ulm. Blood. 2002 Dec 15; 100(13):4372-4380. [PubMed: 12393388]

15. Kottaridis PD, Gale RE, Frew ME, et al. The presence of a FLT3 internal tandem duplication in patients with acute myeloid leukemia (AML) adds important prognostic information to cytogenetic risk group and response to the first cycle of chemotherapy: analysis of 854 patients from the United Kingdom Medical Research Council AML 10 and 12 trials. Blood. 2001 Sep 15; 98(6): 1752-1759. [PubMed: 11535508]

16. Meshinchi S, Stirewalt DL, Alonzo TA, et al. Activating mutations of RTK/ras signal transduction pathway in pediatric acute myeloid leukemia. Blood. 2003 Aug 15; 102(4):1474-1479. [PubMed: 12702504]

17. Kiyoi H, Naoe T, Nakano Y, et al. Prognostic implication of FLT3 and N-RAS gene mutations in acute myeloid leukemia. Blood. 1999 May 1; 93(9):3074-3080. [PubMed: 10216104] 
18. Mead AJ, Linch DC, Hills RK, et al. FLT3 tyrosine kinase domain mutations are biologically distinct from and have a significantly more favorable prognosis than FLT3 internal tandem duplications in patients with acute myeloid leukemia. Blood. 2007 Aug 15; 110(4):1262-1270. [PubMed: 17456725]

19. Whitman SP, Ruppert AS, Radmacher MD, et al. FLT3 D835/I836 mutations are associated with poor disease-free survival and a distinct gene-expression signature among younger adults with de novo cytogenetically normal acute myeloid leukemia lacking FLT3 internal tandem duplications. Blood. 2008 Feb 1; 111(3):1552-1559. [PubMed: 17940205]

20. Mead AJ, Gale RE, Hills RK, et al. Conflicting data on the prognostic significance of FLT3/TKD mutations in acute myeloid leukemia might be related to the incidence of biallelic disease. Blood. 2008 Jul 15; 112(2):444-445. author reply 445. [PubMed: 18606888]

21. Kiyoi H, Ohno R, Ueda R, et al. Mechanism of constitutive activation of FLT3 with internal tandem duplication in the juxtamembrane domain. Oncogene. 2002 Apr 11; 21(16):2555-2563. [PubMed: 11971190]

22. Levis M, Tse KF, Smith BD, et al. A FLT3 tyrosine kinase inhibitor is selectively cytotoxic to acute myeloid leukemia blasts harboring FLT3 internal tandem duplication mutations. Blood. 2001 Aug 1; 98(3):885-887. [PubMed: 11468194]

23. Smith BD, Levis M, Beran M, et al. Single-agent CEP-701, a novel FLT3 inhibitor, shows biologic and clinical activity in patients with relapsed or refractory acute myeloid leukemia. Blood. 2004 May 15; 103(10):3669-3676. [PubMed: 14726387]

24. Stone RM, DeAngelo DJ, Klimek V, et al. Acute myeloid leukemia patients with an activating mutation in FLT3 respond to a small molecule FLT3 tyrosine kinase inhibitor, PKC412. Blood. 2004 Sep 2.

25. DeAngelo DJ, Stone RM, Heaney ML, et al. Phase 1 clinical results with tandutinib (MLN518), a novel FLT3 antagonist, in patients with acute myelogenous leukemia or high-risk myelodysplastic syndrome: safety, pharmacokinetics, and pharmacodynamics. Blood. 2006 Dec 1; 108(12):36743681. [PubMed: 16902153]

26. Mori S, Cortes J, Kantarjian H, et al. Potential role of sorafenib in the treatment of acute myeloid leukemia. Leuk Lymphoma. 2008 Dec; 49(12):2246-2255. [PubMed: 19052971]

27. Metzelder S, Wang Y, Wollmer E, et al. Compassionate use of sorafenib in FLT3-ITD-positive acute myeloid leukemia: sustained regression before and after allogeneic stem cell transplantation. Blood. 2009 Jun 25; 113(26):6567-6571. [PubMed: 19389879]

28. Levis M, Ravandi F, Wang E, et al. Results From a Randomized Trial of Salvage Chemotherapy Followed by Lestaurtinib for FLT3 Mutant AML Patients in First Relapse. 2009

29. Kern W, Estey EH. High-dose cytosine arabinoside in the treatment of acute myeloid leukemia: Review of three randomized trials. Cancer. 2006 Jul 1; 107(1):116-124. [PubMed: 16721819]

30. Estey E. Treatment of refractory AML. Leukemia. 1996 Jun; 10(6):932-936. [PubMed: 8667647]

31. Rytting M, Verstovsek S, Garcia-Manero G, et al. Intensively Timed Induction (ITI) Chemotherapy in Adults with Acute Myelogenous Leukemia (AML). Blood. 2007; 110 Abstract 1851.

32. Beran M, Luthra R, Kantarjian H, et al. FLT3 mutation and response to intensive chemotherapy in young adult and elderly patients with normal karyotype. Leuk Res. 2004 Jun; 28(6):547-550. [PubMed: 15120929]

33. Lin P, Jones D, Medeiros LJ, et al. Activating FLT3 mutations are detectable in chronic and blast phase of chronic myeloproliferative disorders other than chronic myeloid leukemia. Am J Clin Pathol. 2006 Oct; 126(4):530-533. [PubMed: 16938665]

34. Kottaridis PD, Gale RE, Langabeer SE, et al. Studies of FLT3 mutations in paired presentation and relapse samples from patients with acute myeloid leukemia: implications for the role of FLT3 mutations in leukemogenesis, minimal residual disease detection, and possible therapy with FLT3 inhibitors. Blood. 2002 Oct 1; 100(7):2393-2398. [PubMed: 12239147] 


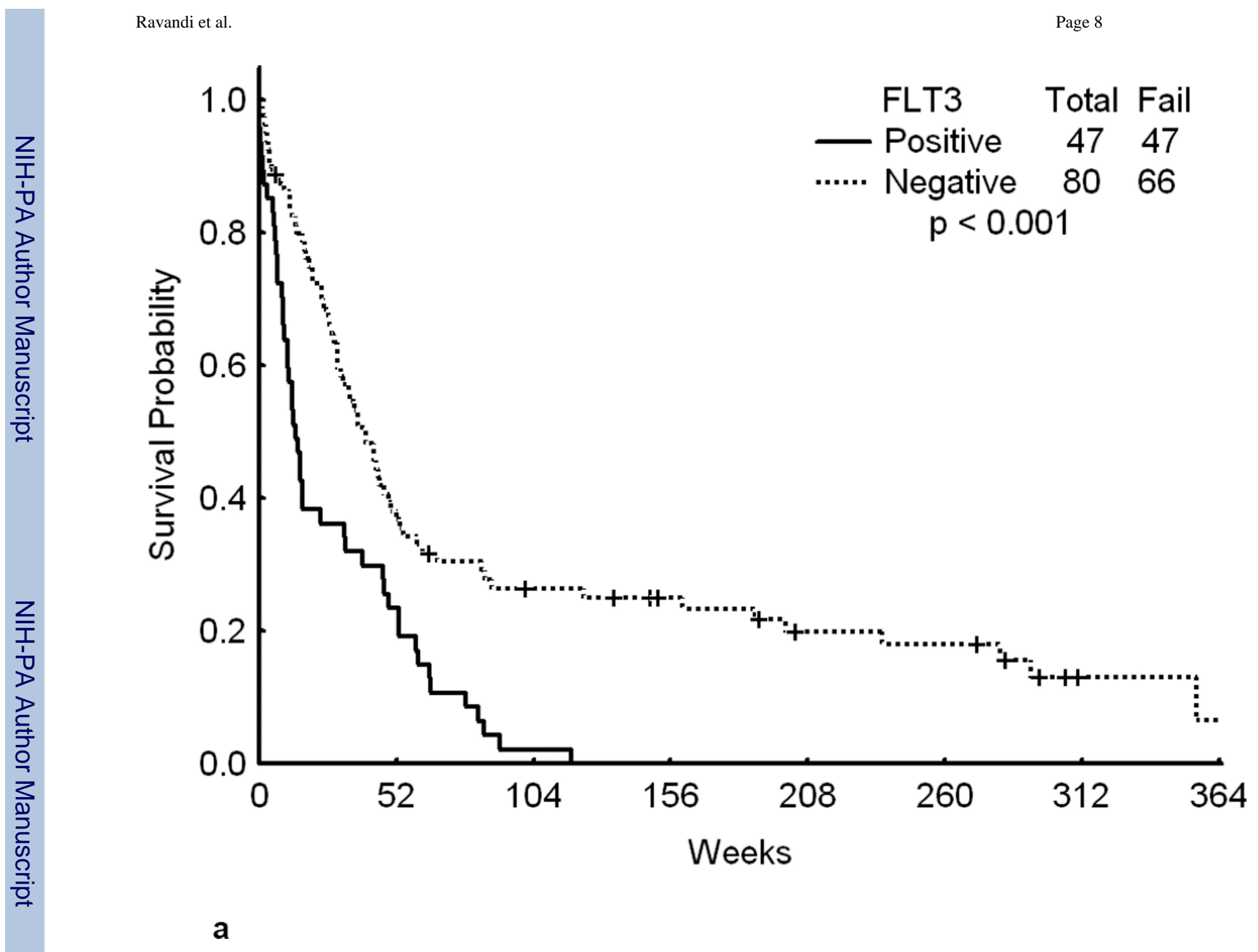

Leuk Res. Author manuscript; available in PMC 2014 July 05. 
b

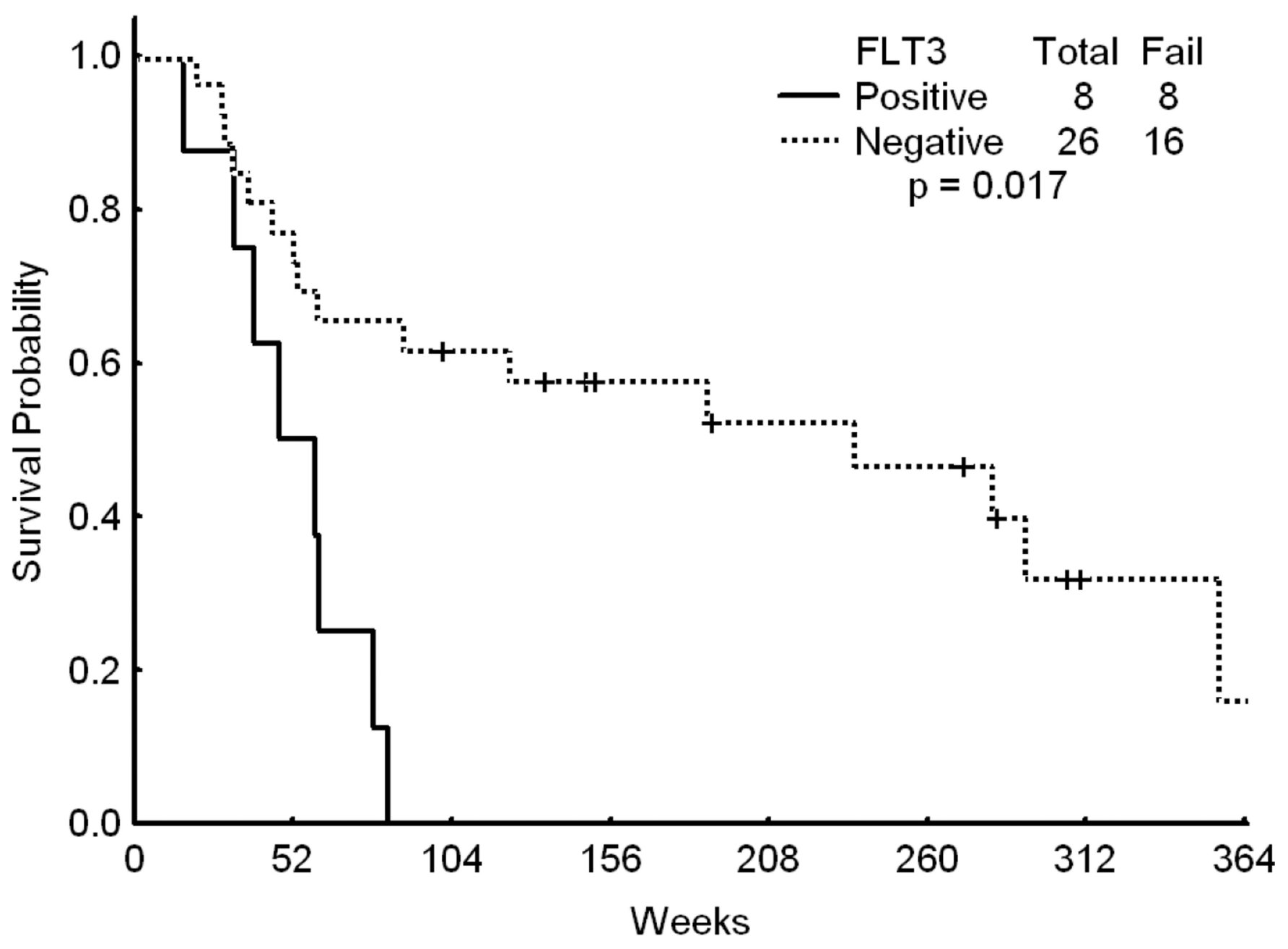




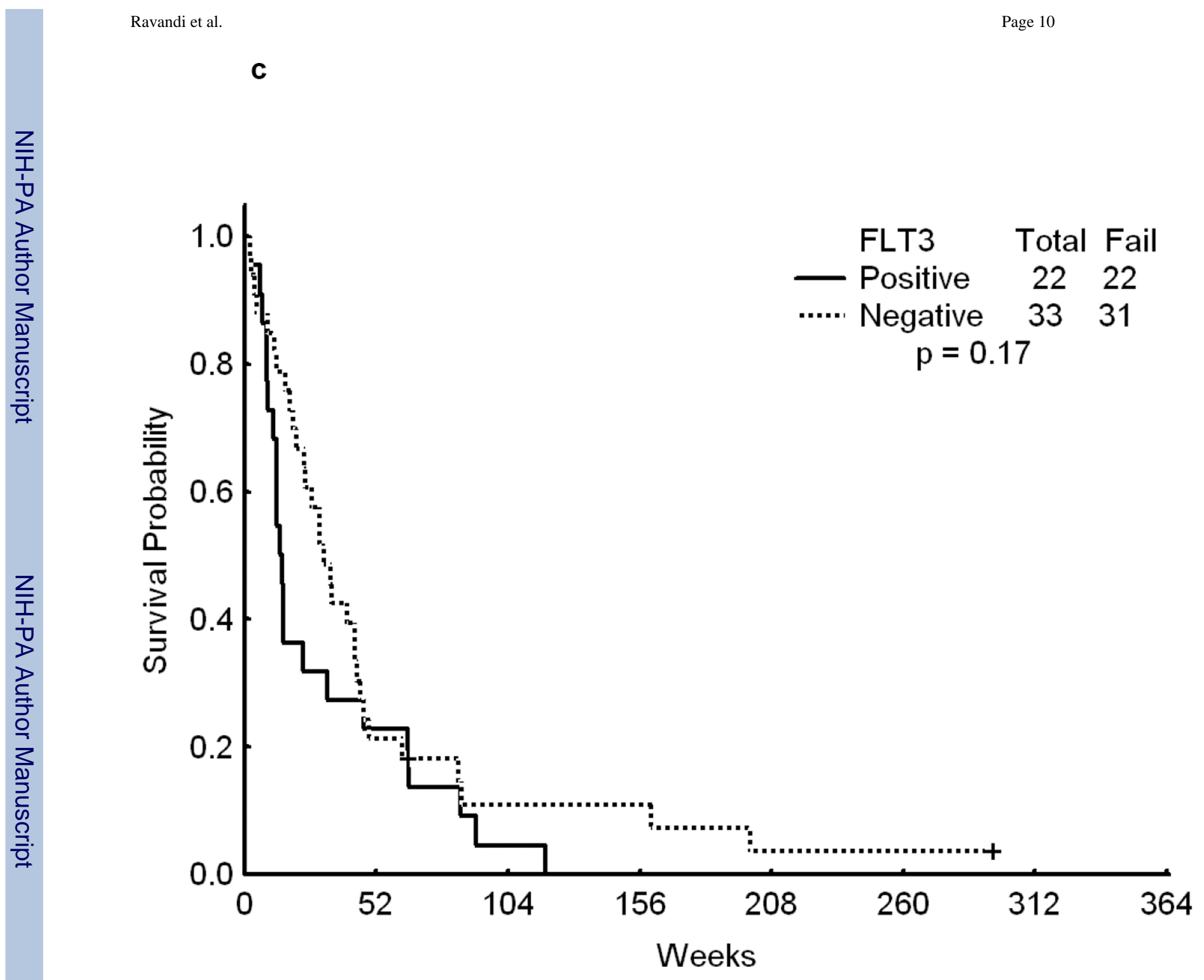


d

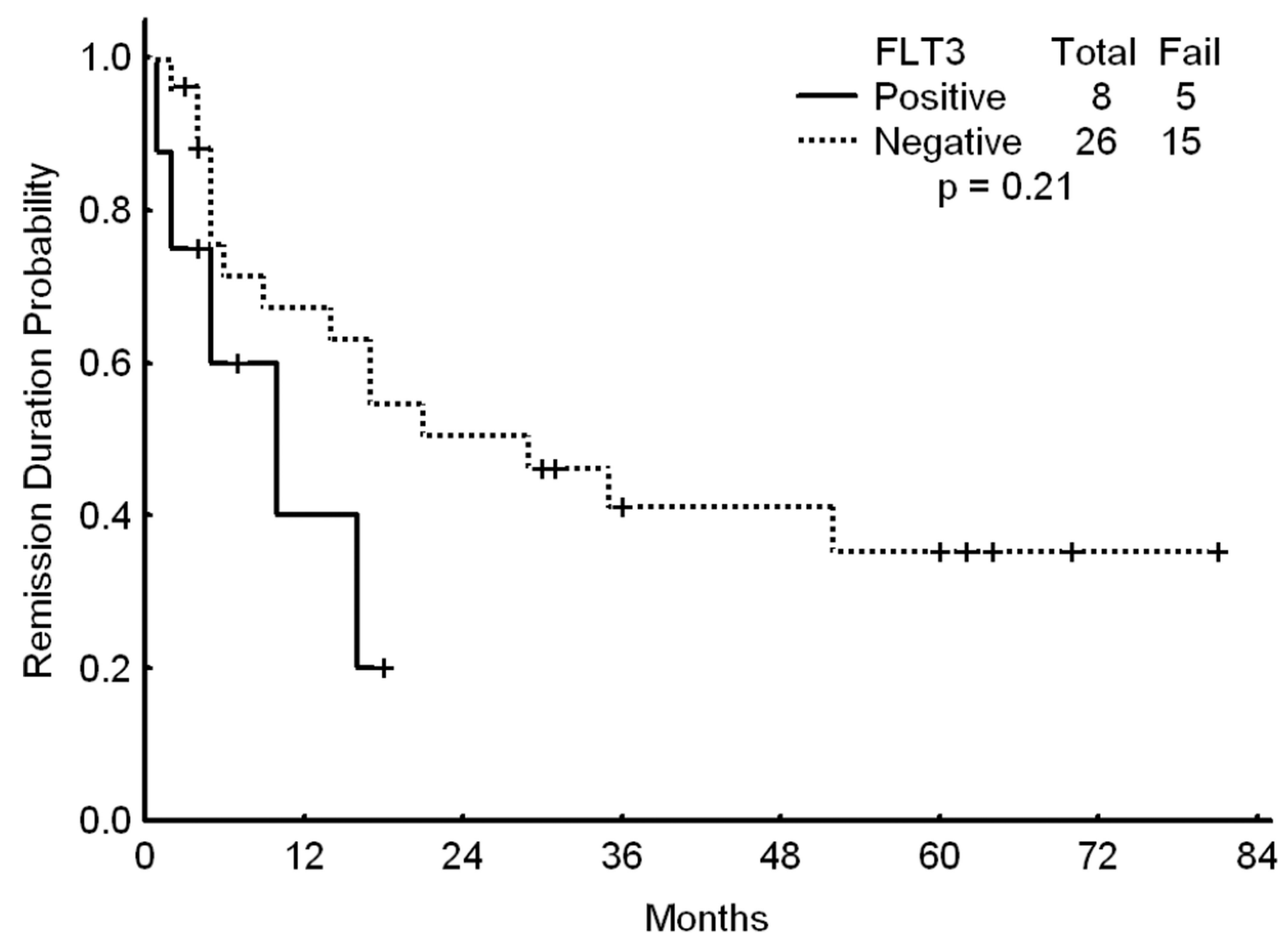

Fig 1.

a - Overall survival from the time of relapse for all patients in first relapse by FLT3 status. b - Survival for patients who achieved CR to first salvage. Time is in Weeks from relapse date to last follow-up.

c - Survival for patients who were resistant to first salvage. Time is in Weeks from relapse date to last follow-up.

d - CR Duration after first Salvage therapy -Time is indicated in Months from date of second CR to either relapse or last follow-up. 


\section{Table 1}

History, characteristics outcome of AML patients in first relapse by FLT3 status (1994-2005)

\begin{tabular}{|c|c|c|c|}
\hline \multirow[t]{2}{*}{ Variable } & \multicolumn{3}{|c|}{$\begin{array}{c}\text { FLT3 status at } \\
\text { presentation }\end{array}$} \\
\hline & $\begin{array}{c}\text { FLT3 WT } \\
\text { N }(\%)\end{array}$ & $\underset{(\%)}{\text { FLT3 Mutant N }}$ & P value \\
\hline Patient in cohort (n) & 221 & $93(85)$ & \\
\hline Receiving HDAC based Induction & $175(79)$ & 109 & 0.18 \\
\hline Achieved CR & $139(63)$ & $66(61)$ & 0.68 \\
\hline Relapsed (n) & $80(56)$ & $47(71)$ & 0.06 \\
\hline Age in years at relapse, Median (range) & $61(19-84)$ & $55(20-83)$ & 0.29 \\
\hline WBC at relapse $\times 10^{9} / \mathrm{L}$ Median (range) & $3.5(0.4-66.0)$ & $20.0(1.8-154.8)$ & $<0.001$ \\
\hline $1^{\text {st }}$ CR duration (weeks), Median (range) & $40(7-290)$ & $28(4-237)$ & 0.77 \\
\hline Received treatment & $74(93)$ & $36(77)$ & 0.01 \\
\hline Received treatment & $69 *(86)$ & $34^{*}(72)$ & 0.81 \\
\hline Median survival from Relapse (weeks) & $37(1-369)$ & $13(0-119)$ & $<0.001$ \\
\hline
\end{tabular}

CR: Complete remission; WT: wild type;

* 5 and 2 patients in WT and Mutant groups were lost to follow-up after receiving treatment. 


\section{Table 2}

Treatment of patients in first relapse

\begin{tabular}{lcc}
\hline Treatment & FLT3 WT & FLT3 Mutated \\
& N & N \\
\hline High dose ara-C & 35 & 17 \\
Allogeneic transplant & 10 & 2 \\
Single agent & 16 & 12 \\
Other intensive & 8 & 3 \\
Total included in analysis & 69 & 34 \\
\hline No treatment & 2 & 7 \\
CEP701 trial & 0 & 4 \\
Lost to FU & 9 & 2 \\
Overall total & 80 & 47 \\
\hline
\end{tabular}

WT: wild type; FU: follow-up 
Table 3

Overall response to salvage chemotherapy in $1^{\text {st }}$ relapse of 189 AML patients by FLT3 status

\begin{tabular}{lccc}
\hline & \multicolumn{3}{c}{ FLT3 Status } \\
\cline { 2 - 4 } Response & $\begin{array}{c}\text { Wild type } \\
\text { N }(\%)\end{array}$ & $\begin{array}{c}\text { Mutated } \\
\text { N }(\%)\end{array}$ & p-value \\
\hline CR+CRP & $26+2(41)$ & $8(24)$ & 0.09 \\
PR & $3(4)$ & 0 & \\
Early Death & $3(4)$ & $3(9)$ & \\
Resistant & $33(48)$ & $22(65)$ & \\
Death Unknown & $2(3)$ & $1(3)$ & \\
Total & 69 & 34 & \\
\hline
\end{tabular}

CR: complete response; PR: partial response 


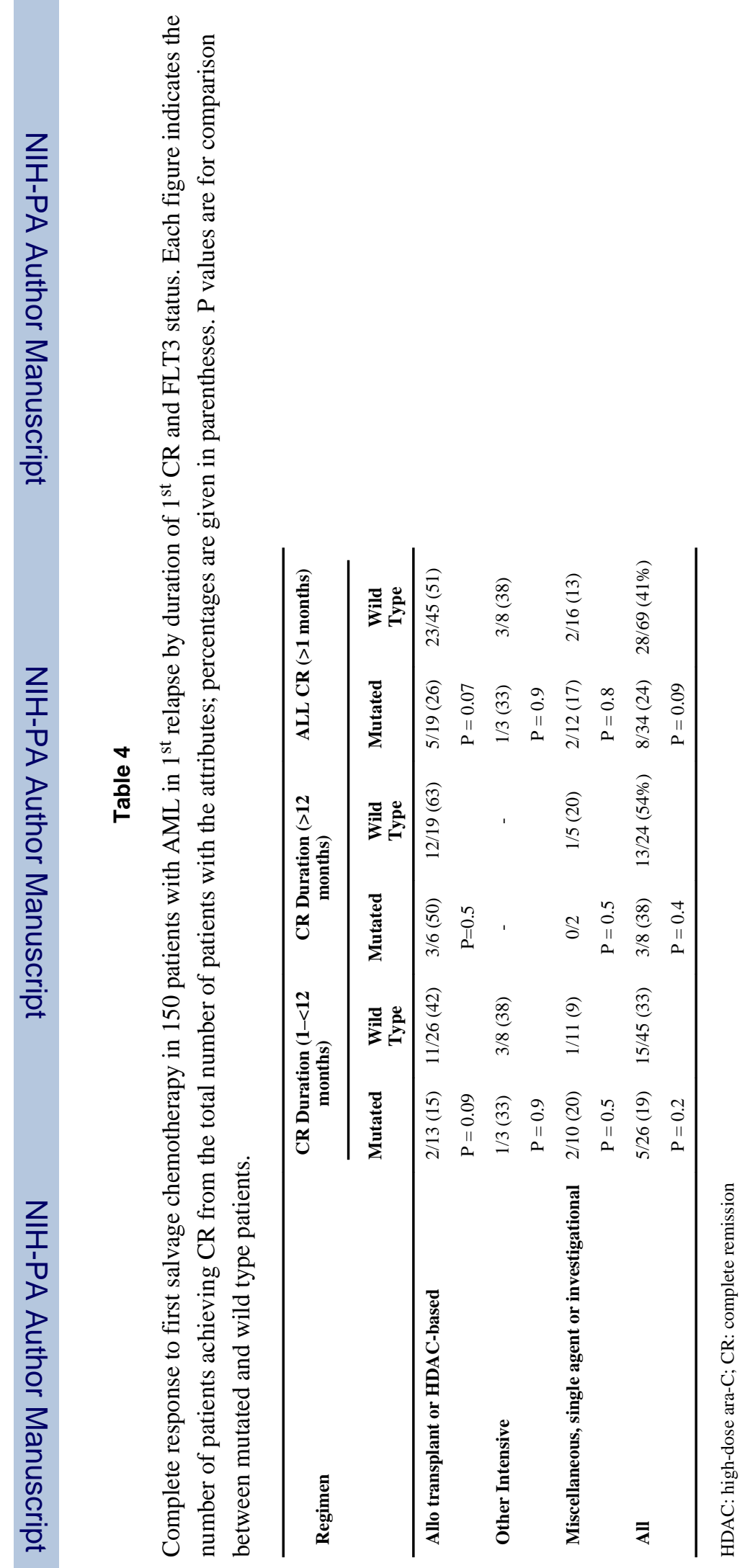

